\title{
Consumer Products using Triclosan as Antimicrobial Agent in the Tropical Environment: Safe or Unsafe?
}

\author{
Maiwada $\mathrm{AS}^{1 *}$ and Abdulkadir $\mathrm{B}^{2}$ \\ ${ }^{1}$ Department of Geography, Umaru Musa Yar'adua University, Nigeria \\ ${ }^{2}$ Department of Microbiology, Umaru Musa Yar'adua University, Nigeria
}

Submission: January 11, 2019; Published: February 25, 2019

*Corresponding author: Maiwada AS, Department of Geography, Umaru Musa Yar'adua University, Nigeria

\begin{abstract}
The tropical environments of the world receive the highest solar radiation throughout the year with an average annual temperature of not less than $18^{\circ} \mathrm{C}$. The use of triclosan as an antimicrobial agent in consumer products such as toothpastes, mouthwash, soaps, under arm deodorants, liquid dishwashing soap and household equipment like textiles materials, toys and plastic kitchenware in this environment exponentially increased over the last few decades and its ability to form low chlorinated dioxins (polychlorinated dibenzodioxins and polychlorinated dibenzofurans) on intense solar radiation and incineration has posed a great risk potential to human health and the aquatic environments. This article aimed to create awareness to the general public on the potentially associated risks of using Triclosan containing materials and its possible implications on human health and the aquatic environments. Humans and aquatic animals get in contact with triclosan through oral, dermal, inhalation and accidental ocular exposures. In many temperate developed countries like US, UK, Canada and Australia, risk assessments were conducted on triclosan and its associated risks to Human health and aquatic environment, despites its traces in human body fluids and aquatic animal tissues, it is concluded that triclosan entering the environment in a way that poses no threat to humanity and aquatic lives. This conclusion came up with lots of uncertainties and conservatism especially due to a lack of adequate data to fully characterize the exposure to triclosan for the representation of the general population, dose estimation and conversion of spot urine samples for all age groups, adequacy of the margin of exposure (MOEs) and spatial differences between places. Moreover, in-depth research on triclosan and its potentialities to affect human health and the aquatic environment is strongly recommended especially in the developing tropical countries in order to create awareness to the general public.
\end{abstract}

Keywords: Aquatic environment; Consumer products; Human health; Potential effects; Triclosan

\section{Introduction}

The bisphenols are class of compounds that exhibit a broad range of spectrum in antimicrobial activity. Among the most widely used members of this group is triclosan $(2,4,4$ '-trichloro2 '-hydroxy-diphenyl ether). It is a material used as a preservative and as an antimicrobial ingredient in a variety of consumer products in order to deodorize and stop the growth of bacteria, fungi and mildew [1]. It was first manufactured by Ciba-Giegy Co under the trade name of Irgasan DP 300 or irgasan MP [2] with OPP Chemical Codes: 054901, CAS Registry No: 3380-34-5, Case Number: 2340 and a Molecular Formula: [3].

In its physical form, Triclosan appears as a white to off white crystalline powder with a slight faint aromatic odour and also commercially available in solid form. It has a Melting point of $54^{\circ} \mathrm{C}-57.3^{\circ} \mathrm{C}$, decompose in temperature of about $280^{\circ} \mathrm{C}-290^{\circ} \mathrm{C}$ , a density of $1.55 \mathrm{~g} / \mathrm{cm}^{3}$ at $22^{\circ} \mathrm{C}$, specific gravity of $1.58 \pm 0.03$ and an auto ignition temperature of $>350^{\circ} \mathrm{C}$ (NICNAS 2009). Chemically, it is hydrologically stable, relatively non-volatile with a vapour pressure of $7 \times 10^{-4}$ pa at $25^{\circ} \mathrm{C}$ and is sparingly soluble in water with solubility of $12 \mathrm{mg} / \mathrm{L}$ at $2^{\circ} \mathrm{C}$, moderately soluble in dilute alkaline solutions, and readily soluble in most organic solvents [4]. Triclosan in powder form is highly stable to intense radiation and solutions may show instabilities when exposed to intense UV-light radiation [5].

Over the last 30 years, this biocide (Triclosan) has become the most potent and extensively used in a variety of consumer products such mouthwash, toothpaste, soaps, deodorants and house hold equipment like textiles (e.g. underwear and socks,), toys, liquid dishwashing soap, and plastic kitchenware $[1,6]$ Triclosan is identified as a liphophilic compound (log Kow=4.8) with ability to form low chlorinated dioxins on incineration or under the influence of sunlight, and under certain circumstances even more highly chlorinated isomers [1] These low-level dioxin substances and toxic contaminants are polychlorinated dibenzodioxins (PCDDs) and polychlorinated dibenzofurans (PCDFs). These substances are a complex mixture of compounds with similar environmental chemical and toxicological 
properties, they are simultaneously found in the samples of fish, meat and other dairy products 1992) [7]. These dioxins are said to have constituted a family of toxic pollutants and have shown potential effects in animal and humans [8]. For this reason, many countries like Canada, USA and Australia prohibited the use of triclosan in cosmetic and other consumer products.

The increased use of Triclosan in the consumer products and Household facilities over the decades has raised a lot of concern especially in terms of human health and aquatic environmental contamination. In view of that, the aim of this review is to create awareness to the general public on the potential risks on using triclosan containing consumer products and possible implications to human health and aquatic environment especially in the tropics.

\section{Human Exposure to Triclosan}

As previously shown in many studies, triclosan is found in the plasma, urine and milk from large parts of different human population. The potential sources of exposure to triclosan include consumer products treated with or containing triclosan, drinking water contaminated with triclosan, breast milk and contaminated household dust [9].

\section{Dermal exposure}

Studies shows that triclosan is relatively well absorbed through the skin in all tested species, Human's application of products containing triclosan is dependent on the formulation, applied dose, duration of exposure, type of skin and skin $[10,11]$ revealed that triclosan concentrations were higher in both plasma and milks from the mothers who used personal care products containing triclosan than in the mothers who did not. The triclosan concentrations were significantly higher in the exposed group.

\section{Oral exposure}

Triclosan is currently included as an antibacterial agent in many types of toothpastes and mouthwashes sold globally. As a result, individuals become chronically exposed to the agent once or twice a day in conjunction with brushing teeth [12] The substance reaches the systemic circulation via absorption through the mucous membranes of the oral cavity and of the gastrointestinal tract, thus initiating a systemic exposure. It was revealed that triclosan containing toothpaste and mouthwashes are considered to be the main sources of the varying triclosan concentrations found in a large part of the population in Sweden [13] Infant's exposure to triclosan through breastfeeding can be considered as Oral exposure though indirect. Thus, their exposure to triclosan was related to the mothers' exposure and the concentrations indicated that infant exposure to triclosan via breast milk is much less than the dose in the mother [11].

\section{Inhalation exposure}

Rapid development in industrialization over the past years has resulted in the increased use of new chemicals in the consumer products and household facilities like triclosan treated clothing, cosmetics, carpets and toys. This makes the chemical concentrations often higher indoors. Furthermore, people spend about $90 \%$ of their time indoors [14]. Inhalation exposure to triclosan is expected to be negligible except in the industrial setting.

Accidental ocular exposure: During occupational use of triclosan powder, solutions and triclosan containing end-use products accidental ocular exposure may occur. It is expected to occur only infrequently and will involve very small amounts of triclosan. Therefore, the potential for public exposure via this route is expected to be negligible [15].

\section{Human health risks potentials}

Carcinogenic potentials: It has been previously suggested that chemicals with oestrogenic properties applied in body care cosmetics around the breast area could be a contributory factor in the rising issues of breast cancers [16]. This be consistent with the increasing use of cosmetic products in the under-arm area. Even though, it could be inconsistent with the dogma that the high incidence of breast cancer in the upper quadrant of the breast relates solely to the slightly greater amount of breast epithelial tissue in that region [17]. Many other body tissues apart from the mammary gland are also sensitive to oestrogen action, not least reproductive organs, skin, bone and the cardiovascular system and this means that with the continued use of parabens in so wide a range of skincare products lies a great carcinogenic potential [18].

Genotoxic potentials: Due to the dramatic increase in the use of triclosan in common products and its emergence in the aquatic ecosystems, e.g., Surface water, fish tissue as well as in sewage treatment plant influents and effluents. Triclosan may act on molecules, cells and organs in different organisms through unexpected modes of action [19]. The literature about the potential genotoxicity of triclosan is controversial because positive and negative effects have been reported in the same biological models in both bacterial and mammalian cells [20].

Potential thyroid hormone effects: Recently triclosan has been shown to alter endocrine function in a variety of species. Due to the concerns about its known environmental contamination, the endocrine disrupting properties seen in various systems and the potential for triclosan to have adverse effects on human health. Many studies have clearly demonstrated that triclosan suppresses serum T4 concentrations in a dose-dependent manner in the juvenile male rat [21]. Because triclosan is present in such a variety of personal care and household products, in the ecosystem, and in human body fluids, there is a potential concern for adverse effects on human health.

Immunotoxicity potentials: A previous study has shown that triclosan is able to disturb placental hormone secretion and cell survival of human chorio-carcinoma JEG-3 cells. The human placenta is responsible for the production of a number 
of hormones necessary for normal fetal development and pregnancy maintenance, such as progesterone and oestrogens $[22,23]$ demonstrated that triclosan is able to inhibit the sulfotransferase and glucuronosyltransferase enzymatic activities in human liver cytosolic and microsomal fractions. Triclosan also showed a positive association with hay fever diagnosis in the less than 18-year age group $(\mathrm{p}<0.01)$, although its levels were not associated with cytomegalovirus antibody levels. These studies have multiple limitations, which makes the ability of triclosan to affect the immune system needed further studied.

\section{Human Health risk Assessment conducted on Triclosan}

Risk assessment has been made on the use of triclosan and its risk to human health. Exposure to triclosan is estimated by comparing mean and upper-bounding exposure estimates in humans with critical effect levels in health effects studies conducted in laboratory animals in order to derive margins of exposure (MOEs). For the general population, comparison of the estimated mean and upper-bound daily intakes with critical effect levels in mice (based on liver effects) resulted in MOEs between 700 and 13000 [24].

The carcinogenic potential of triclosan was reviewed based on chronic toxicity and carcinogenicity study in hamsters, carcinogenicity studies in mice and rats, metabolism and mutagenicity studies, as well as additional documentation regarding the significance of the mouse study results for human health. It was determined that there was a sufficient weight of evidence supporting activation of peroxisome proliferatoractivated receptor alpha (PPAR $\alpha$ ) as the primary mode of action (MOA) for triclosan-induced hepatocarcinogenesis in the mouse. Furthermore, neither of the carcinogenicity reviews conducted in the rat or hamster provided evidence of a carcinogenic potential to humans [25].

In humans, triclosan is rapidly absorbed and distributed, with plasma levels increasing rapidly within 1-4 hours. Following all routes of administration, absorbed triclosan is said to have been nearly totally converted to glucuronic and sulfuric acid conjugates due to a pronounced first-pass effect, with only trace amounts of the parent compound detected in the plasma. It shows that elimination is rapid with a terminal plasma halflife of 21 hours [26]. Similar to baboons, hamsters, monkeys and rabbits, the major route of excretion is via urine (24-83\%), with the majority of the compound appearing as the glucuronide conjugates. Excretion of triclosan in the faces represents a smaller portion of the administered dose (10-30\%), and it's present as the free unchanged compound [26].

Triclosan has been tested for mutagenic activity in several assays, in vitro, negative results have been seen in numerous studies in bacteria with only a single weakly positive result seen in a brief reported study at a very high dose level. Similarly, no evidence of mutagenic activity was found in fungi or mammalian cells. Thus, the weight of evidence does not indicate any significant genotoxic potential. In vivo, negative results have been seen in a number of bone marrow chromosome aberration and micronucleus studies. Both a negative and positive result has been seen in the mouse spot test though there are limitations in the methodology employed in both studies. Similarly, there are limitations in methodology in the available studies in germ cells that were all negative. Therefore, there is no robust evidence of a genotoxic potential in vivo [15].

Extrapolation shows differences in thyroid hormone homeostasis between humans and rats. In general, humans are considered less sensitive than rats to chemical-induced perturbation in thyroid hormone homeostasis due to the presence of high-affinity binding proteins (thyroxine-binding globulin) in human serum. Thus, it is likely that humans will be less responsive to triclosan induced changes. As well, less than $1 \%$ of humans are freely circulating and available for destruction by liver enzymes, resulting in humans having a greater resistance than the rat to thyroid toxicity, which occur secondary to liver enzyme activation [27].

\section{Uncertainties associated with triclosan risk assessment}

There are uncertainties and conservatisms in conducting the total exposure and risk assessment for the general population due to a lack of adequate data to fully characterize the exposure to triclosan. With regard to the dose estimation, it is unknown if high levels of triclosan in some samples were the result of abundant use of consumer products or the result of an isolated event prior to sampling. For that reason, an assumption of the maximum triclosan concentration detected in human plasma and breast milk is considered conservative.

Another uncertainty is in the dose conversion of spot urine samples for all age groups where there is assumption that absorption, distribution, metabolism and elimination parameters are the same for all individuals and remain constant within individuals over time. There is an uncertainty regarding the potential co-occurrence of all identified scenarios in practice. An assumption that a person will be exposed daily to high triclosan residues as identified for each scenario is considered conservative. The assumption that all potential exposure scenarios will co-occur also represents conservatism in the total assessment. And at last all the developed countries (USA, Canada, Australia and United Kingdom) where risk assessment of triclosan was conducted are located in the temperate regions of the world where temperature is always low unlike the equatorial and tropical developing countries of Africa and Asia where solar radiation is received at very high Intensity.

Although, based upon the adequacy of the margin of exposure (MOEs) derived from laboratory animals, between estimates of aggregated exposure to triclosan and critical effect 
levels in the risk assessment conducted, there is no direct evidence that triclosan is entering the environment in a quantity or concentration or under conditions that constitute or may constitute a danger to human life or health and the aquatic environment. Concerns have been raised over its possible role in allergies, the disruption of endocrine systems and antibiotic resistance. Jones (2000) also proposed that triclosan meets the criterion for bioaccumulation but not the criteria for persistence as set out in the Persistence and Bioaccumulation Regulations.

\section{Conclusion}

Triclosan was found in many samples of human body fluid. For that reason, the potential risk of using consumable products treated or contaminated with triclosan as well as exposure to triclosan is quite alarming, even though generally humans are considered ten times less sensitive than rats when it comes to chemically induced perturbation. Therefore, more in-depth research on triclosan and its potentialities to affect human health and the aquatic environment is strongly recommended especially in the developing tropical countries in order to create awareness to the general public.

\section{References}

1. Adolfsson Erici M, Pettersson M, Parkkonen J, Sturve J (2002) Triclosan, a commonly used bactericide found in human milk and in the aquatic environment in Sweden. Chemosphere 46(9-10): 1485-1489.

2. SanchesSilva A, Sendon Garcia R, Lopez Hernandez J, Paseiro Losada P (2005) Determination of triclosan in foodstuffs. Journal of separation science 28(1): 65-72.

3. US EPA (2008b) Reregistration Eligibility Decision for Triclosan. Office of Prevention. Pesticides and Toxic Substances.

4. Ying G, Kookana R (2007) Triclosan in wastewaters and biosolids from Australian wastewater treatment plants. Environment International 33(2): 199-205.

5. Sanchez Prado L, Llompart M, Lores M, Garcia Jares, C, Bayona J, et al. (2006) Monitoring the photochemical degradation of triclosan in wastewater by UV light and sunlight using solid phase microextraction. Chemosphere 65(8): 1338-1347.

6. Schweizer H (2001) Triclosan: a widely used biocide and its link to antibiotics. FEMS Microbiology Letters 202(1): 1-7.

7. Ahlborg U, Brouwer A, Fingerhut M, Jacobson J, Jacobson S, et al. (1992) Impact of polychlorinated dibenzo-p-dioxins, dibenzofurans, and biphenyls on human and environmental health, with special emphasis on application of the toxic equivalency factor concept. European Journal of Pharmacology: Environmental Toxicology and Pharmacology 228(4): 179-199.

8. Kogevinas M (2001) Human health effects of dioxsins: cancer, reproductive and endocrine system effects. Apmis 109(S103): 223232.

9. US EPA (2008a) Triclosan: Occupational and residential exposure assessment. Office of Pesticide Programs, Antimicrobials Division, Washington (DC).

10. Queckenberg C, Meins J, Wachall B, Doroshyenko O, Tomalik Scharte D, et al. (2010) Absorption, pharmacokinetics, and safety of triclosan after dermal administration. Antimicrobial agents and chemotherapy 54(1): 570-572.
11. Allmyr M, Adolfsson Erici M, McLachlan M, Sandborgh Englund G (2006) Triclosan in plasma and milk from Swedish nursing mothers and their exposure via personal care products. Science of the Total Environment 372(1): 87-93.

12. Jones R, Jampani H, Newman J, Lee A (2000) Triclosan: a review of effectiveness and safety in health care settings. American journal of infection control 28(2): 184-196.

13. Sandborgh Englund G, Adolfsson Erici M, Odham G, Ekstrand J (2006) Pharmacokinetics of triclosan following oral ingestion in humans. Journal of Toxicology and Environmental Health Part A 69(20): 18611873.

14. Rudel R, Perovich L (2009) Endocrine disrupting chemicals in indoor and outdoor air. Atmospheric Environment 43(1): 170-181.

15. NICNAS (2009) Triclosan: Priority existing chemical assessment report No. 30 Australian Government Department of Health and Ageing.

16. Darbre P, Aljarrah A, Miller W, Coldham N, Sauer M, et al. (2004) Concentrations of parabens in human breast tumours. Journal of applied toxicology 24(1): 5-13

17. Darbre P, Harvey P (2008) Paraben esters: review of recent studies of endocrine toxicity, absorption, esterase and human exposure, and discussion of potential human health risks. Journal of Applied Toxicology 28(5): 561-578.

18. Shen H, Jiang H, Mao H, Pan G, Zhou L, et al. (2007) Simultaneous determination of seven phthalates and four parabens in cosmetic products using HPLC-DAD and GC-MS methods. Journal of separation science 30(1): 48-54.

19. Binelli A, Cogni D, Parolini M, Riva C, Provini A (2009) Cytotoxic and genotoxic effects of in vitro exposure to Triclosan and Trimethoprim on zebra mussel (Dreissena polymorpha) hemocytes. Comparative Biochemistry and Physiology Part C: Toxicology Pharmacology 150(1): 50-56.

20. Abou Eisha A (2006) Evaluation of cytogenetic and DNA damage induced by the antibacterial drug, trimethoprim. Toxicology in vitro 20(5): 601607.

21.Zorrilla L, Gibson E, Jeffay S, Crofton K, Setzer W, et al. (2009) The effects of triclosan on puberty and thyroid hormones in male Wistar rats. Toxicological Science 107(1): 56-64.

22. Honkisz E, Zieba Przybylska D, Wojtowicz A (2012) The effect of triclosan on hormone secretion and viability of human choriocarcinoma JEG-3 cells. Reproductive Toxicology 34(3): 385-392.

23. Wang L, Falany C, James M (2004) Triclosan as a substrate and inhibitor of $3^{\prime}$-phosphoadenosine $5^{\prime}$-phosphosulfate-sulfotransferase and UDPglucuronosyl transferase in human liver fractions. Drug metabolism and disposition 32(10): 1162-1169.

24. HCEC (2012) Triclosan: Preliminary Assessment. Chemical abstract registry number 3380, pp. 34-35.

25. US EPA (2008c) Cancer assessment document: evaluation of the carcinogenic potential of triclosan. Washington (DC): Office of Prevention, Pesticides and Toxic Substances.

26. SCCP (2009) Opinion on Triclosan. COLIPA No. P32. Health \& Consumer Protection Directorate-General, European Commission.

27. Choksi N, Jahnke G, St Hilaire C, Shelby M (2003) Role of thyroid hormones in human and laboratory animal reproductive health. Birth Defects Research Part B: Developmental and Reproductive Toxicology 68(6): 479-491. 
This work is licensed under Creative Commons Attribution 4.0 License DOI: 10.19080/CTBEB.2019.18.555989
Your next submission with Juniper Publishers

will reach you the below assets

- Quality Editorial service

- Swift Peer Review

- Reprints availability

- E-prints Service

- Manuscript Podcast for convenient understanding

- Global attainment for your research

- Manuscript accessibility in different formats

( Pdf, E-pub, Full Text, Audio)

- Unceasing customer service

Track the below URL for one-step submission https://juniperpublishers.com/online-submission.php 